\title{
The prospect of using the cyanobacterium Nostoc muscorum to improve vital activity of barley seedlings by various methods of seed treatment
}

\author{
Ekaterina $V$. Koval ${ }^{1, *}$, Svetlana $Y u$. Ogorodnikova ${ }^{2,3}$ \\ ${ }^{1}$ FSBEI HE "Northern Trans-Ural State Agricultural University", Agrotechnological Institute, 625003 \\ Tyumen, Respubliki st., 7, Russia. \\ ${ }^{2}$ Institute of Biology of the Komi Scientific Center, Ural Branch of the Russian Academy of Sciences, \\ 167982 Syktyvkar, Kommunisticheskaya str., 28, Russia. \\ ${ }^{3}$ Vyatka State University, Institute of Chemistry and Ecology, 610000 Kirov, Moscowskaya str., 36, \\ Russia.
}

\begin{abstract}
The influence of the cyanobacterium Nostoc muscorum on vital activity of barley seedlings of the species Novichok was researched. In the experiments different ways of cyanobacterial treatment were used: introducing microorganisms in the growth medium and pre-sowing inoculation of barley seeds with cyanobacteria. The influence of cyanobacterial treatment on biochemical indices and linear growth of barley plants was assessed. The share of plastid pigments and intensity of the processes of lipid peroxidation were assessed in a spectrophotometric way, standard methods were applied. It was stated that Nostoc muscorum has a phytostimulating effect which consists in inhibiting oxidation processes in barley cells, accumulating substances with antioxidative activity, and activating growth processes. Pre-sowing inoculation of barley seeds with cyanobacteria is the most effective one.
\end{abstract}

\section{Introduction}

Cyanobacteria (CB) is a group of gram-negative morphologically various procaryotes, they include one-celled, colonical, and filamentary forms. They are the most ancient organisms upon the Earth and they are ubiquitous, they live everywhere, including hot springs, water bodies and soils of different type, even polluted ones. CB are able to form symbioses with different organisms, including plants. Cyanobacterial symbioses can be of different types: epithytical (CB concentrate on outer surfaces), which is typical of the genus Nostoc with the moss (Sphagnum); endophytic (CB concentrate within intercellular spaces), which is typical of Nostoc or Anabaena with some mosses, ferns, and gymnosperms; intracellular (CB concentrate within filaments or vesicles), for example, Nostoc with herbaceous plants of the genus Gunnera $[1,2]$. United organisms form a single entity with its structural and

\footnotetext{
*Corresponding author: koval.ev@gausz.ru
} 
functional links, a slime layer of $\mathrm{CB}$, as a rule, takes part in their formation [3]. Such cyanobacterial and plant complexes are less vulnerable to unfavourable influence of the environment $[4,5]$.

Mechanisms of this sustainability are various. For example, CB can contain or their satellite bacteria can produce protective agents, such as flavacin, polysaccharids, phenazine pigments, hormone-like elements, etc., which lowers the risk of fungal and bacterial infections of plants, improves mineral nutrition of their growth-stimulating effect; all that can produce a growth-stimulating effect on and cause immunity increase in plants [6].

This effect depends on the amount of produces of metabolites and the species of the symbiont plant. Thus it is quite promising to use CB as part of microbiologic agents used in forestry and agriculture, in plants' immunostimulation and growth activation.

Nowadays there are many biopreparations used in the process of presowing seed inoculation in order to lessen infection damage and stimulate growth [7, 8]. Besides, using effective microorganisms as a means of presowing seed treatment is considered ecologically safe and useful both for seeds and for the environment. There are preparations for soil treatment which optimize vital activity and improve mineral nutrition. So seed treatment is an important method of yield enhancement and increasing plants' population.

The aim of the paper is to research the influence of the CB Nostoc muscorum on biochemical indices and on growth of barley seedlings and to find out the most effective way of cyanobacterial treatment of plants.

\section{Materials and Method}

The object of the research is barley of the species Novichok, the choice of the object is determined by its high ecomonic value. Barley is widely used in food industry, in feedstuff production. $70 \%$ of barley yield is used for these purposes [9].

In the research the autotrophic cyanobacteria Nostoc muscorum ag. № 13 (strain 13) was used. The strain was isolated and identified from chernozem of the Kursk region, Russia. The originator of the species is Tretyakova Alevtina Nikolayevna, Candidate of Biology. For the research the CB pure culture was grown at continuous illumination (3000 lux) at the steady temperature of $+25^{\circ} \mathrm{C}$ on nitrogen-free Gromov liquid medium №6.

During the research two sets of experiments were made in order to find out the most effective way of cyanobacterial treatment of barley. In the first set of experiments the influence of the additive CB N. muscorum in the plants' growth medium of was researched. During 7 days barley seeds were couched in Petri plates on distilled water. Then the seedlings were placed in reservoirs in water culture on Knop medium (control variant) and on Knop medium with the CB (experimental variant). In the second set of experiments the effect of barley seeds inoculation with $\mathrm{CB} N$. muscorum at the germination stage was researched. Seeds of experimental plants were cultivated on distilled water either with the homogenized CB suspension or without it (control) in Petri plates. Later seven-days-old seedlings were transplanted into plates with Knop nutrient solution.

During the experiments CB N. muscorum was used at the stage of exponential growth : in the first set of experiments -10 weeks, titer $1.4 \cdot 10^{5}$ cells $/ \mathrm{ml}$; in the second set of experiments -9 weeks, titer $6.5 \cdot 10^{7}$ cells $/ \mathrm{ml}$. Cells titer was calculeated with the method of direct count in the Goryaev chamber [10]. After 14 days of germination the influence of cyanobacterial treatment on morphometrical and biochemical characteristics of barley seedlings was studied. The intensity of processes of lipid peroxidation (LPO) was assessed judging from the amount of malondialdehyde [11]. Accumulation of chlorophyll $a, \sigma$ and carotenoids was assessed spectrephotometrically in aceton extrate [12]. The experiments were repeated 3 times in a laboratory in accordance with the requirements of the 
corresponding methods. The results were statistically processed and presented as mean values and their standard deviations $(\mathrm{x} \pm \delta)$.

\section{Results and Discussion}

It was stated that $\mathrm{CB}$ in the growth medium cause some change in intensity of oxidation processes in barley cells. One of the markers of the process of LPO is the minor metabolite malondialdehyde (MDA). In the roots of barley grown on the medium with $\mathrm{CB}$ the level of MDA was less by $20 \%$, as compared with the control (Table). Probably, low intensituy of LPO processes in roots in case of long incubation with CB is conditioned by a good effect of $\mathrm{CB}$ exometabolites on heterotrophic tissues. It is known that $\mathrm{CB}$ exometabolites contain substances with an antioxidative activity [13].

Table. Influence of different methods of cyanobacterial treatment with Nostoc muscorum on biochemical parameters of barley plants.

\begin{tabular}{|c|c|c|c|c|}
\hline \multirow{2}{*}{ Variant } & \multicolumn{2}{|c|}{ Malondialdehyde, $\mathrm{nmol} / \mathrm{g}$} & \multicolumn{2}{|c|}{ Pigments, mg / g dry weight } \\
\hline & leaves & roots & chlorophylls $(a+b)$ & carotenoids \\
\hline \multicolumn{5}{|c|}{$\mathrm{CB}$ in the growing medium } \\
\hline Control & $11.00 \pm 0.36$ & $27.50 \pm 0.98$ & $7.57 \pm 1.37$ & $1.24 \pm 0.17$ \\
\hline $\begin{array}{l}\text { Nostoc } \\
\text { muscorum }\end{array}$ & $12.23 \pm 0.25 *$ & $21.94 \pm 0.64 *$ & $11.94 \pm 0.37 *$ & $1.7 \pm 0.08^{*}$ \\
\hline \multicolumn{5}{|c|}{ Inoculation of seeds with $\mathrm{CB}$} \\
\hline Control & $13.37 \pm 0.86$ & $6.16 \pm 0.51$ & $7.26 \pm 0.43$ & $0.86 \pm 0.11$ \\
\hline $\begin{array}{l}\text { Nostoc } \\
\text { muscorum }\end{array}$ & $4.94 \pm 1.18^{*}$ & $3.37 \pm 0.35^{*}$ & $7.35 \pm 0.17$ & $1.98 \pm 0.01 *$ \\
\hline
\end{tabular}

Note: * - differences are significant compared with the control at $\mathrm{P} \leq 0.5$.

Presence of CB in the growth medium causes biochemical changes in the above-ground organs, which suggests systematic effect of $\mathrm{CB}$ on a plant organism. In barley leaves the intensity of LPO processes was close to that of the control plants (Table). High concentration of carotenoids (1.4 times higher) was stated in the leaves of barley grown with $\mathrm{CB}$. The fact is that carotenoids have a protective effect in a cell : in case of interaction with organic residuals of fatty acides they act as knock-outs of the residuals [14]. Accumulation of carotenoids can suggest activation of the antioxidant system caused by CB influence. Efficienncy of antioxidant defense is also proved by the total share of chlorophylls, green pigments, in the leaves. In case of presence of CB N. muscorum in the growth medium the amount of chlorophylls in barley leaves was by $60 \%$ higher, as compared with the control.

Inoculation of seeds with $N$. muscorum during germination caused more prominent transformations of biochemical processes in barley cells. Probably, during seeds treatment with $\mathrm{CB}$ the maximum contact with seeds is achieved, barley leaf and root tissues get bacterized with $\mathrm{CB}$, plant-cyanobacterial associations form, and they have a phytostimulating effect. It was stated that seeds treatment with $\mathrm{CB}$ contributed to considerable, more than 2 times higher, inhibition of LPO processes in barley roots and leaves (Table). In case of seeds treatment, as well as in the experiments with $\mathrm{CB}$ introduction in growth medium, the share of yellow pigments, carotenoids, was increased in barley leaves (Table). There is a considerable negative correlation between the share of carotenoids and the intensity of LPO processes in barley leaves $(\mathrm{r}=-0.83)$, which suggests 
activation of the antioxidant system in plant tissues as a reaction to seeds inoculation with N. muscorum. The share of chlorophylls in barley leaves was close to the control (Table).

CB treatment of plants causes change in biochemical processes in cells; probably, it is caused by the influence of biologically active metabolites of CB. Metabolic rearrangements in cells are reflected in the change of growth processes.

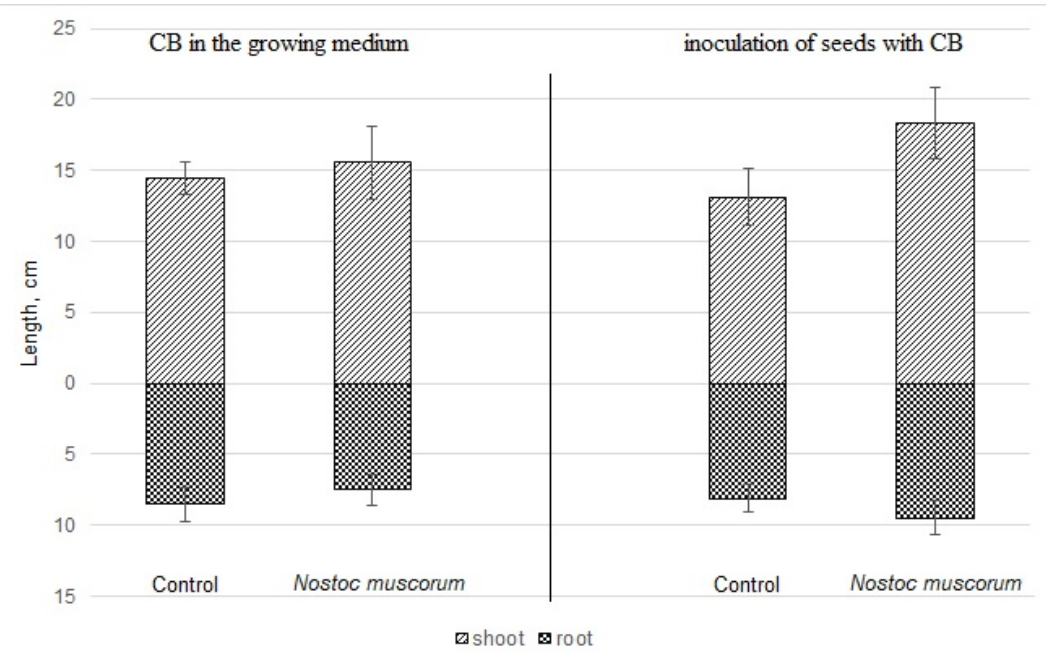

Fig. Influence of different methods of cyanobacterial treatment with Nostoc muscorum on growth of barley plants.

Presence of $N$. muscorum in the growth medium did not have any influence on growth of shoots and roofs of barley (Figure). On the contrary, seeds inoculation with CB had a growth-stimulating effect on barley seedlings, the plants were by $40 \%$ higher, as compared with the control. It was visually noticeable that barley leaves were longer and broader, there were no necroses or chloroses on them. In the experiment with seeds treatment with $\mathrm{CB}$ barley roots were by $17 \%$ higher, as compared with the control. It had been stated before that in case of inoculation of wheat seedlings with the CB Nostoc sp., it can penetrate in roots. They were found in intercellular space, as well as inside cortex and epidermal cells of the plant [1]. Probably, growth stimulation is connected with the ability of CB and their satellite-bacteria to produce auxin- and giberellin-like substances which, in conditions of long mutual exposition of $\mathrm{CB}$ and seedlings, penetrate into plant tissues. $\mathrm{CB}$ stimulate growth of barley seedlings.

\section{Conclusion}

In the model experiment the influence of different ways of treatment with $\mathrm{CB}$ N. muscorum on biochemical and growth indices of barley plants was researched. The most effective way of treatment of seedlings in order to improve their vital activity is inoculation of seeds with N. muscorum. Presowing cyanobacterial treatment of seeds contributes to improvement of biochemical parameters, such as inhibition of LPO processes in leaves and roots, stimulating the antioxidant system and, consequently, growth of plants.

On the whole, the cyanobacterium $N$. muscorum has a definite phytostimulating effect and improves biochemical characteristics of barley. So, using this species of CB for incresing seedlings' vital activity and for making biological preparations on the basis of the $\mathrm{CB}$ for agriculture and forest management is rather promising. 
The authors are grateful to the Department of Plant Biology, selection and seed breeding, microbiology named after E.A. Shtina VSATU (Russia, Kirov) for the provided culture of cyanobacteria.

\section{References}

1. M. Gantar, Biol. Fertil. Soils 32 (3), 390-395 (2000)

2. I.A. Tikhonovich, N.A. Provorov, Biotechnol. J. 2, 833-848 (2007)

3. L. Pengfu, E. Stephen Harding, L. Zhili, Biotechnology and Genetic Engineering Reviews 18, 375-404 (2001)

4. A.N. Rai, B. Bergman, U. Rasmussen, Cyanobacteria in Symbiosis, 346 (Dordrecht, Netherlands, 2002)

5. A.I. Fokina, S.Yu. Ogorodnikova, L.I. Domracheva, E.I. Lyalina, E.A. Gornostaeva, T. Ya. Ashikhmina, L.V. Kondakova, Eurasian Soil Science 50 (1), 70-77 (2017)

6. L.I. Domracheva, S.G. Skugoreva, A.I. Fokina, M.A. Zagoskin, T.Y. Ashikhmina,. South of Russia: ecology, development 16(1), 53-60 (2021)

7. E.M. Pankratova, L.V. Trefilova, R.Yu. Zyablykh, I.A. Ustyuzhanin, Microbiology, 77 (2), 228-234 (2008)

8. K. Raja, K. Sivasubramaniam, R. Anandham, Journal of Applied Horticulture (Lucknow) 21 (3), 195-200 (2019)

9. T. Akar, M. Avci, F. Dusunceli. Barley: Post Harvest Operations in Developing Countries. Food and Agriculture Organisation of the United Nations, 53 pp (2004)

10. M.S. Muntyan, D.A. Morozov, S.S. Klishin, N.V. Khitrin, G.Ya. Kolomijtseva, Biochemistry, 77(8), 1113 (2012)

11. A.S. Lukatkin, Cold damage to heat-loving plants and oxidative stress, 208 (Publishing house of Mordov. University: Saransk, Russia, 2002)

12. A.A. Shlyk. Determination of chlorophylls and carotenoids in extracts green leaves, Biochemical methods in plant physiology, 154-170 (Moscow, Russia 1971)

13. A.I. Fokina, L.I. Domracheva, S.Yu. Ogorodnikova, Principy èkologii 3, 133-143 (2019)

14. A.J. Young, Physiol Plant 83, 702-708 (2006) 